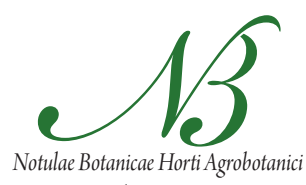

Cluj-Napoca

\title{
Determination of Apomictic Fruit Set Ratio in Several Romanian Walnut (Juglans regia L.) Cultivars
}

\author{
Sina COSMULESCU ${ }^{1 *}$, Mihai BOTU ${ }^{1,2}$, Gheorghe ACHIM ${ }^{1,2}$ \\ ${ }^{1}$ University of Craiova, Department of Horticulture and Food Science, Agriculture and Horticulture Faculty, 13 \\ A.I.Cuza Street, 200585, Craiova, Romania; sinacosmulescu@hotmail.com (*corresponding author) \\ ${ }^{2}$ University of Craiova, SCDP Valcea, 464 Calea lui Traian Str., 240273, Ramnicu Valcea, \\ Romania;btmihai@hotmail.com,gheorgheachim555@yahoo.com
}

\begin{abstract}
Apomixis, a natural process that allows clonal propagation by seed, is an important feature of walnut (Juglans regia L.). This study was carried out to determine the ability of apomictic fruit setting in twelve Romanian walnut cultivars. 'Sibisel 44', 'Geoagiu 65', 'Germisara', 'Muscelean', 'Sarmis,' 'Valcor,' 'Valmit,' 'Valrex,' 'Jupanesti,', Velnita,' 'Orastie' and 'Argesean' cultivars were used in the experiment. Female flowers were isolated with pergament paper bags and the apomictic fruit set was determined 8 weeks after anthesis. The apomixis degree was determined as the number of fruit calculated in relation to the number of isolated flowers. The percentage of apomictic fruit set without pollination in cultivars analyzed is low, ranging from $7.86 \%$ ('Orastie' cultivar) up to $12.46 \%$ ('Jupanesti' cultivar). The results indicated that apomictic fruit set is insufficient for economical seed and crop production in these Romanian walnut cultivars.
\end{abstract}

Keywords: apomictic rate, bloom date, cultivars, dichogamy, Juglans regia

\section{Introduction}

Apomixis is a natural trait of reproduction in plants where the embryo is formed without the union of male and female gametes. Plants produce fruits with genetically identical seeds to their female parent (Ulukan, 2009). Apomixis provides a method of clonally propagating plants through seed (Koltunow et al., 2001; Spillane et al., 2001) and is of great interest owing to its potential application in crop improvement (Albertini et al., 2009).

Walnut (Juglans regia L.) is a heterozygous plant. Research conducted in walnut fruit formation, have shown that some of the genotypes can form fruits without fecundation, through parthenocarpy or apomixis. Opportunities for fruit formation without pollination in walnut, under normal conditions, have raised a keen interest among researchers in biology of flowering and seed formation (Badalov, 1983; Germain et al., 1973; Hanna and Bashaw, 1987; Laiko, 1990; Valdiviesso, 1990). In terms of economic analysis, the phenomenon of parthenocarpy is undesirable because some of the fruits resulted in this way are small, dry, with no commercial value. Fruit formation by apomixis, has, however, theoretical and practical importance; the embryo is homozygous and it accurately transmits the characters of mother plant. Thus, walnut breeders can use apomixis in traditional breeding programs for cultivar improvement (Guo-Liang et al., 2007; Hanna, 1995).

Many researchers have reported apomixis in walnut (Germain et al., 1973; Laiko, 1990; Şan and Dumanoğlu,
2006; Valdiviesso, 1990), but it was found that the formation of fruit is weak, almost zero in some cases, so there is no apomictic crop to be expected. Sometimes apomixis percentage is higher, between $23.5 \%$ and $81.2 \%$, in some of the genotypes (Laiko, 1990; Solar et al., 1995), but apomictic nuts cannot be always obtained. A higher percentage of fruit formation through apomixis (the average apomixis rate in walnut was $38.25 \%$, while the highest value was $78.6 \%$ ) is described by Guo-Liang et al. (2007) under conditions in China.

Guoliang et al. (2010) reported a new cultivar of walnut tree ('Qinquan 1'), which was selected from walnut seedling resources in the Northern China and characterized by apomixis; the average apomixis rate was $48.53 \%$, and the highest rate could reach up to $75.7 \%$ (Wu et al., 2010). Under conditions in Turkey, the percentage of apomictic fruits has varied between $0.5 \%$ and $1.6 \%$ (Şan and Dumanoğlu, 2006). Asadian and Pieber (2005) reported a maximum apomixis percentage of $58 \%$ in 'Milotai $4 / \mathrm{R}$ ' variety, in the experiments carried out in Austria, and Valdiviesso (1990) showed that the growth of apomictic fruits in 'Rego' cv. was 7\% in Portugal.

In Romania there were found no cultivars or types to possess valuable features of apomixis (Cosmulescu, 2003). Experiments made on walnut types in Oltenia showed that they are characterized by a low ability to form fruits without pollination. Among all isolated flowers, the percentage of fruits obtained was between $0-4.3 \%$ (Cosmulescu, 2003). 
230

Having in view that apomixis-an asexual method of reproduction through the seed- provides unique opportunities for developing superior cultivars in the future (Hanna and Bashaw, 1987), the objective of this study was to determine the genetic potential for apomixis in Romanian walnut cultivars. Identification of apomictic cultivars is an important issue for solving the genetic variation.

\section{Materials and methods}

The experiments were conducted at the experimental walnut orchard (Fig. 1) belonging to the University of Craiova and located at SCDP Valcea Research Station, Romania ( $45^{\circ} 08^{\prime} \mathrm{N}$ and $24^{\circ} 22^{\prime} \mathrm{E}$ ). The study period was over 3 years (2008-2011). During this period, the average annual temperature in the area was $11.3^{\circ} \mathrm{C}\left(1.1^{\circ} \mathrm{C}\right.$ more than the multi-annual average). The absolute minimum temperatures and the lack of spring frosts have not caused damages to catkins and female walnut flowers. The annual average of rainfall was $771.5 \mathrm{~mm}(59.5 \mathrm{~mm}$ more than the multi-annual average). Twelve Romanian walnut cultivars (18 to 20 year-old trees), with different types of flowering, different pistillate bloom dates (Cosmulescu et al., 2010a) and good quality fruits (Cosmulescu et al., 2009, 2010b) were tested (Tab. 1).


Tab. 1. Cultivars, type of flowering and bearing of walnut cultivars

\begin{tabular}{cccc}
\hline No. & Cultivar & Type of dichogamy & $\begin{array}{c}\text { The pistillate } \\
\text { bloom dates }\end{array}$ \\
\hline 1 & 'Sarmis' & protogynous & early/ semi-early \\
2 & 'Sibisel 44' & protogynous & early/ semi-early \\
3 & 'Valcor' & protogynous & early/ semi-early \\
4 & 'Valmit' & protogynous & early \\
5 & 'Valrex' & protogynous & early/ semi-early \\
6 & 'Jupanesti' & protandrous & semi-early / semi-late \\
7 & 'Argesean' & protogynous & early/ semi-early \\
8 & 'Geoagiu 65' & protogynous & early/ semi-early \\
9 & 'Germisara' & protogynous & early/ semi-early \\
10 & 'Muscelean' & protandrous & early \\
11 & 'Orastie' & protogynous & early/ semi-early \\
12 & 'Velnita' & protogynous & early/ semi-early \\
\hline
\end{tabular}

*early (April 20-30), semi-early (May 1-5), semi-late (May 6-10),late (after May 10)

A number of flowers were randomly chosen and then isolated with pergamin paper pocket. Before bagging, any male flowers were removed. Bags were removed after 10 to 15 days, when stigmata were fully dry, and the formation of apomictic seeds was determined 8 weeks after anthesis. The apomixis degree was determined as the number of fruits calculated in relation to the number of isolated
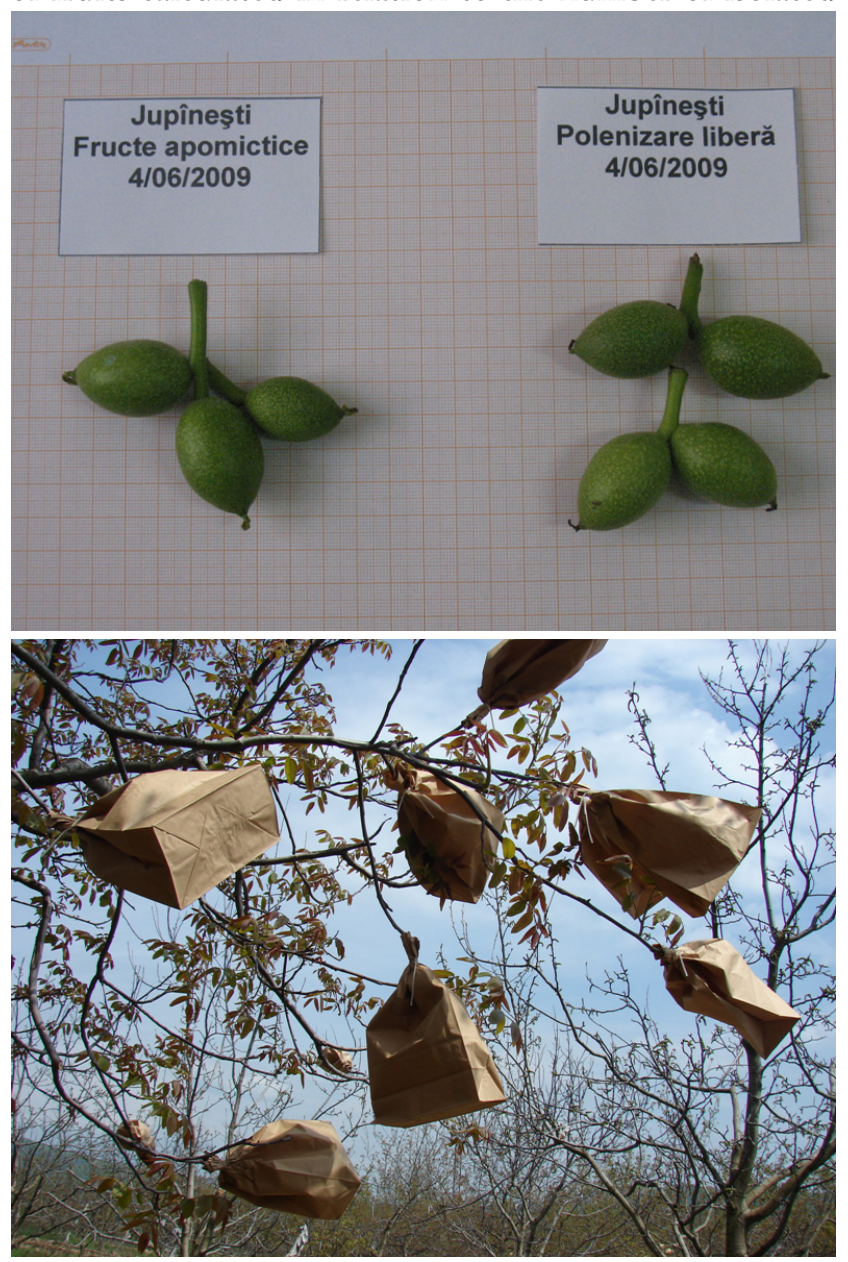

Fig. 1. Research field images 
Tab. 2. Descriptive statistics for apomictic rate in twelve Romanian walnut cultivars analyzed

\begin{tabular}{|c|c|c|c|c|c|c|c|c|c|c|c|c|}
\hline $\begin{array}{c}\text { Cultivars / descriptive } \\
\text { statistics }\end{array}$ & 'Sarmis' & 'Sibisel 44' & 'Valcor' & 'Valmit' & 'Valrex' & 'Jupanesti' & 'Argesan' & 'Geoagiu 65' & 'Germisara' & 'Muscelean' & 'Orastie' & 'Velnita' \\
\hline Mean & 9.83 & 10.16 & 11.13 & 10.43 & 9.43 & 12.46 & 8 & 9.53 & 9.33 & 8.36 & 7.86 & 9.66 \\
\hline Standard Error & 1.87 & 1.07 & 2.58 & 2.10 & 1.50 & 2.32 & 0.79 & 1.30 & 1.71 & 0.78 & 0.84 & 1.86 \\
\hline Standard Deviation & 3.25 & 1.85 & 4.48 & 3.65 & 2.60 & 4.02 & 1.37 & 2.25 & 2.96 & 1.36 & 1.45 & 3.23 \\
\hline Sample Variance & 10.58 & 3.45 & 20.12 & 13.32 & 6.80 & 16.16 & 1.89 & 5.08 & 8.81 & 1.86 & 2.12 & 10.45 \\
\hline Range & 6.5 & 3.4 & 8.3 & 6.8 & 4.9 & 8 & 2.7 & 4.5 & 5.8 & 2.7 & 2.7 & 5.6 \\
\hline Minimum & 6.5 & 8.9 & 6 & 7.8 & 7.5 & 8.7 & 6.5 & 7.2 & 6.8 & 6.9 & 6.2 & 7.8 \\
\hline Maximum & 13 & 12.3 & 14.3 & 14.6 & 12.4 & 16.7 & 9.2 & 11.7 & 12.6 & 9.6 & 8.9 & 13.4 \\
\hline
\end{tabular}

Tab. 3. Analysis of apomixis rate diferences between pairs of walnut cultivars with multiple range $t$ test

\begin{tabular}{|c|c|c|c|c|c|c|c|c|c|c|c|}
\hline & 'Valcor' & 'Valmit' & 'Sibisel 44' & 'Sarmis' & 'Velnita' & 'Geoagiu 65' & 'Valrex' & 'Germisara' & 'Muscelean' & 'Argesan' & 'Orastie' \\
\hline 'Jupanesti' & 1.33 & 2.03 & $2.30^{*}$ & $2.63^{*}$ & $2.80^{*}$ & $2.93^{*}$ & $3.03^{*}$ & $3.13^{* *}$ & $4.10^{* *}$ & $4.47^{* * *}$ & $4.60^{* * *}$ \\
\hline 'Valcor' & & 0.70 & 0.97 & 1.30 & 1.47 & 1.60 & 1.70 & 1.80 & $2.77^{*}$ & $3.13^{* *}$ & $3.27^{* *}$ \\
\hline 'Valmit' & & & 0.27 & 0.60 & 0.77 & 0.90 & 1.00 & 1.10 & 2.07 & $2.43^{*}$ & $2.57^{*}$ \\
\hline 'Sibisel 44' & & & & 0.33 & 0.50 & 0.63 & 0.73 & 0.83 & 1.80 & 2.17 & $2.30^{*}$ \\
\hline 'Sarmis' & & & & & 0.17 & 0.30 & 0.40 & 0.50 & 1.47 & 1.83 & 1.97 \\
\hline 'Velnita' & & & & & & 0.13 & 0.23 & 0.33 & 1.30 & 1.67 & 1.80 \\
\hline 'Geoagiu 65' & & & & & & & 0.10 & 0.20 & 1.17 & 1.53 & 1.67 \\
\hline 'Valrex' & & & & & & & & 0.10 & 1.07 & 1.43 & 1.57 \\
\hline 'Germisara' & & & & & & & & & 0.97 & 1.33 & 1.47 \\
\hline 'Muscelean' & & & & & & & & & & 0.37 & 0.50 \\
\hline 'Argesean' & & & & & & & & & & & 0.13 \\
\hline
\end{tabular}


232

flowers. Experiments were repeated over 3 years. Similar methodologies were used by other authors (Guo-Liang et al., 2007; Şan and Dumanoğlu, 2006).

The data were analyzed by using Microsoft Excel ${ }^{\circ}$, Descriptive Statistics. Mean comparisons were performed by using multiple range $t$ test to examine if differences between cultivars were significant at $p<0.05$.

\section{Results and discussion}

The twelve cultivars examined have diverse apomictic capacity (Tab. 2). Their average annual apomictic rate ranged from $7.86 \%$ ('Orastie' cultivar) up to $12.46 \%$ ('Jupanesti' cultivar). An apomixis rate higher than $10 \%$ (average rate over the 3 years) was recorded in only four cultivars ('Jupanesti', 'Valcor,' 'Valmit,' 'Sibisel 44'). Variance analysis showed that the apomictic rate has significantly differed between the cultivars and years. Apomictic ability of 'Jupanesti' was the highest (12.46\%), but the difference of their average value $(8.7 \% / 16.7 \%)$ was greater than three years. 'Valcor' cultivar had the highest difference of apomictic rate over the three years $(6 \% / 14.3 \%)$, which were affected by variation (20.12). A low variation of apomixis rate was recorded in cultivars 'Orastie' (2.12\%), 'Argesean' (1.89\%) and 'Muscelean' (1.86\%).

In comparing with other results obtained in different cultivars and other ecological conditions, the apomixis rate found in cultivars analyzed is low. Solar et al. (1995) reported that apomixis rates were very high in some walnut genotypes; the average degree of apomixis ranging from $23.5 \%$ ('G-26') to $31.5 \%$ ('Elit'). According to Soylu and Ertürk (2001), the apomictic fruit set in the 1974/7 walnut type was $36 \%$. Four of the walnut cultivars examined by Guo-Liang et al. (2007) had apomictic tendencies and their average apomictic rate was $38.25 \%$; the highest observed rate was $78.6 \%$.

The results obtained in the cultivars analyzed in this study indicated that apomictic fruit set is insufficient for economic seed and crop production in the Romanian walnut cultivars. The result is in accordance with the previous research. Soylu and Ertürk (2001) reported that apomictic fruit set ratio in 'Yalova 2' walnut cultivar was 4\%; Valdiviesso (1990) stated for 'Rego' cv the rate of 7\% growth of apomictic fruits; and Gao et al. (1999) found out that apomixis rates of four apomixis varieties were between $1.5 \%$ and $13.0 \%$.

In the present study, the differences among the cultivars are statistically significant. Analysis of apomixis rate diferences between pairs of walnut cultivars with multiple range $t$ test (Tab. 3) showed the existence of important differences among cultivars. The cultivar 'Jupanesti' was shown to be notably different in apomixis rate from 'Orastie' and 'Argesean' cultivars (differences from them were 4.60 and $4.47 \%$, respectively); while it was not much differing from 'Valmit' and 'Valcor' (differences were 2.03 and $1.33 \%$, respectively). Differences recorded in apomixis rate in culti- vars studied are likely caused by environmental conditions; a fact that was upheld by other researchers too (Guo-Liang et al., 2007). Regarding the correlation between type of dichogamy, the pistillate bloom dates and apomixis rate, the literature upholds that apomixis is more common in protandrous cultivars than in the protogynous ones; and genotypes with late flowering are forming parthenocarpic fruits more often than those with early flowering. Probably the apomixis percentage of $12.46 \%$ obtained in 'Jupanesti' cultivar would have an explanation in the flowering time (semi-early / semi-late) and protandrous type of dichogamy. The same explanation could be used for other cultivars too, which are forming fruits with no late pollination (in nursery), because flowering and fecundation occur over a period when pollen source is missing. The research conclusion was in accordance with that of Solar et al. (1995), who considers that the average degree of apomixis is high in late leafing cultivars.

\section{Conclusions}

The results of flower's bagging isolation showed that the twelve tested Romanian walnut cultivars have differed in terms of apomictic ability, and the average apomictic rate was between $7.86 \%$ and $12.46 \%$. Apomictic ability was significantly different both over the years and among the cultivars. These data indicate that apomictic fruit set is insufficient to assure economical seed and crop production in walnut genotypes.

\section{Acknowledgements}

This work was supported by the Romanian CNCSIS-UEFISCSU, project number PNII- IDEI code 430 $/ 2008$.

\section{References}

Albertini E, Barcaccia G, Mazzucato A, Sharbel TF, Falcinelli M (2009). Apomixis in the era of biotechnology, p. 405-436. In: Pua EC, Davey M (Eds.). Plant Developmental Biology -Biotechnological Perspectives: Volume 1, Berlin, Springer Verlag.

Asadian G, Pieber K (2005). Morphological variations in walnut varieties of the Mediterranean regions. Internat J Agricult Biol 7:71-73.

Badalov PP (1983). The use of methods of hybridization and apomixis for obtaining the perspective forms of walnut. Forest Prod 12:24-25 (in Russian).

Cosmulescu SN (2003). Biological peculiarities in common walnut, p. 30-50. In: Cociu V (Ed.). Culturile Nucifere. Editura Ceres, Bucureşti.

Cosmulescu S, Baciu A, Achim G, Botu M, Trandafir I (2009). Mineral composition of fruits in different walnut (Juglans regia L.) cultivars. Not Bot Horti Agrobo 37(2):156-160.

Cosmulescu S, Baciu A, Botu M, Achim GH (2010a). 
Environmental factors' influence on walnut flowering. Acta Hort 861:83-88.

Cosmulescu S, Trandafir I, Achim G, Botu M, Baciu A, Gruia $\mathrm{M}$ (2010b). Phenolics of green husk in mature walnut fruits. Not Bot Horti Agrobo 38(1):53-56.

Gao S, Liu C, Liu D, Li L, Ye N, Chen Y (1999). Apomixis Characteristics of Juglans regia L. J Northwest For Univ 14(1):45-47.

Germain E, Jalinat J, Marchou M (1973). Biologie florale du noyer. Bull. Technol. Inform. Min Agr Development Rurale FR. N282:661-673.

Guoliang W, He L, Qunlong L, Yong W, Pengfei Z (2010). 'Qinquan 1', a new apomixis walnut cultivar. Fruits 65:3942

Guo-Liang W, Yan-hui C, Peng-fei Z, Yang Jun-qiang Y, Yu-qin $S$ (2007). Apomixis and new selections of walnut. Acta Hort 760:541-548.

Hanna WW (1995). Use of apomixis in cultivar development. Adv Agron 54:333-350.

Hanna WW, Bashaw EC (1987). Apomixis: its identification and use in plant breeding. Crop Sci 27(6):1136-1139.

Koltunow AM, Scott NS, Chaudhury AM (2001). The use of apomixis in cloning horticultural plants: current applications and molecular prospects. Acta Hort 560:333-343.

Laiko RE (1990). Apomixis of walnut. Acta Hort 284:233236.
Solar A, Smole J, Simonic S (1995). The ability of apomictic fruit setting in five walnut cultivars (Juglans regia L.). Zbornik Biotehniske Fakultete Univerze v Ljubljani, Kmetijstvo 65:103-110.

Soylu A, Ertürk Ü (2001). Research on apomictic seed formation in some walnut cultivars. Proceedings of Turkey First National Symposium on Walnut, Tokat (Turkey), 133$137 \mathrm{p}$.

Spillane C, Steimer A, Grossniklaus U (2001). Apomixis in agriculture: the quest for clonal seeds. Sexual Plant Reproduct 14(4):179-187.

Şan B, Dumanoğlu H (2006). Determination of the apomictic fruit set ratio in some Turkish walnut (Juglans regia L.) genotypes. Turk J Agric For 30:189-193.

Ulukan H (2009). A new alternative for plant breedings, biodiversity and environmental sustainability: apomictics. J Biol Sci 9(8):788-795.

Valdiviesso T (1990). Apomixis in Portuguese walnut varieties. Acta Hort 284:279-283.

Wu GL, Hou LQ, Zhang ZH, Tian JB (2010). New chinese cultivar resources of Juglans with special characteristics. Acta Hort 861:155-162. 